\title{
Characterization of cinnamyl alcohol dehydrogenase of Helicobacter pylori
}

\section{An aldehyde dismutating enzyme}

\author{
Blanaid Mee ${ }^{1}$, Dermot Kelleher ${ }^{2}$, Jesus Frias ${ }^{1}$, Renee Malone ${ }^{1}$, Keith F. Tipton ${ }^{3}$, \\ Gary T.M. Henehan ${ }^{1}$ and Henry J. Windle ${ }^{2}$ \\ 1 School of Food Science and Environmental Health, Dublin Institute of Technology, Ireland \\ 2 Department of Clinical Medicine, Trinity College Dublin, Ireland \\ 3 Department of Biochemistry, Trinity College Dublin, Ireland
}

\author{
Keywords \\ aldehyde; cinnamyl alcohol dehydrogenase; \\ dismutation; Helicobacter pylori; lignin

\section{Correspondence} \\ G. Henehan, School of Environmental \\ Health and Food Science, Dublin Institute of \\ Technology, Ireland \\ E-mail: Gary.Henehan@DIT.ie
}

(Received 17 November 2004, revised 6 January 2005, accepted 7 January 2005)

doi:10.1111/j.1742-4658.2005.04561.x
Cinnamyl alcohol dehydrogenases (CAD; 1.1.1.195) catalyse the reversible conversion of $p$-hydroxycinnamaldehydes to their corresponding alcohols, leading to the biosynthesis of lignin in plants. Outside of plants their role is less defined. The gene for cinnamyl alcohol dehydrogenase from Helicobacter pylori (HpCAD) was cloned in Escherichia coli and the recombinant enzyme characterized for substrate specificity. The enzyme is a monomer of $42.5 \mathrm{kDa}$ found predominantly in the cytosol of the bacterium. It is specific for $\mathrm{NADP}(\mathrm{H})$ as cofactor and has a broad substrate specificity for alcohol and aldehyde substrates. Its substrate specificity is similar to the well-characterized plant enzymes. High substrate inhibition was observed and a mechanism of competitive inhibition proposed. The enzyme was found to be capable of catalysing the dismutation of benzaldehyde to benzyl alcohol and benzoic acid. This dismutation reaction has not been shown previously for this class of alcohol dehydrogenase and provides the bacterium with a means of reducing aldehyde concentration within the cell.
Cinnamyl alcohol dehydrogenases (CAD; EC 1.1.1.195) are zinc dependent dehydrogenases and are among the least studied of the alcohol dehydrogenase enzymes. The function of CADs in plants has been well characterized, where they have been shown to catalyse the reversible conversion of $p$-hydroxycinnamaldehydes to their corresponding alcohols leading to lignin biosynthesis [1-7].

Outside of plants the role of CAD is less well understood and the enzyme has only been kinetically characterized in two other species, Mycobacterium bovis BCG and Saccharomyces cerevisiae [8-10]. A role for CAD in lipid metabolism within the cell envelope was proposed in M. bovis BCG [8]. In $S$. cerevisiae it has been suggested that CAD may be involved in the Erlich pathway, the process whereby amino acids are degraded, leading to the formation of aldehydes which are subsequently metabolized via the activity of alcohol dehydrogenases (ADHs) to form fusel alcohols [9,10]. Although the CADs of $M$. bovis BCG and S. cerevisiae are not involved in lignin biosynthesis, they have similar substrate specificities to plant CADs.

The annotated genome of $H$. pylori strain 26695 [11] identifies a single putative $C A D$ gene (HP1104) that we have cloned and characterized in an effort to gain a better understanding of this class of CAD outside of plants. The H. pylori CAD (HpCAD) was also of interest as its production was shown to increase 24-fold under acid stress conditions [12] and antibodies to HpCAD have been identified in the sera of gastric cancer patients [13].

\section{Abbreviations}

ADH, alcohol dehydrogenase; HpCAD, Helicobacter pylori cinnamyl alcohol dehydrogenase. 
H. pylori is implicated in the pathogenesis of chronic gastritis and, more recently, in the development of gastric carcinoma [14-17]. The mechanisms whereby this organism causes damage to the gastric mucosa are not fully understood. However, strains possessing the vacuolating toxin (VacA) and the cytotoxin-associated antigen (CagA), which is used as a marker for the insertion of a pathogenicity island (cag PAI), are associated with a higher frequency of duodenal ulcer, atrophic gastritis and gastric carcinoma among infected patients [18]. In addition, other researchers have proposed that ADHs contribute to the pathogenicity of $H$. pylori by metabolizing dietary alcohols to form toxic aldehydes, which interact with the gastric mucosa to cause inflammation [19-27]. This paper reports the genetic cloning, production and characterization of HpCAD and the first demonstration that a member of the CAD family has an aldehyde dismutase activity.

\section{Results}

\section{Overproduction of the $\boldsymbol{H}$. pylori cinnamyl alcohol dehydrogenase}

The putative $C A D$ gene (HP1104) was clearly present in the strains of $H$. pylori tested $(1061,26695$ and G27) (Fig. 1A). The corresponding protein product was detected by Western blotting in the above strains as well as in strain N6 (Fig. 1B). Genomic DNA from the sequenced strain 26695 was used for subsequent cloning studies. The $C A D$ gene was cloned in Escherichia coli DH5 $\alpha$ and the pET-Hp1104 construct containing the cloned gene was transformed into E. coli BL21(DE3)plysS for overexpression. A $600 \mathrm{~mL}$ preparation of pET-Hp1104 transformed E. coli BL21(DE3)plysS typically yielded approximately 12-18 mg of purified CAD. The His-tag on the $\mathrm{N}$ terminus of the expressed HpCAD protein facilitated a one-step affinity purification on a nickel-charged iminodiacetic acid column. The pure fractions of HpCAD eluted from the column were combined and dialysed against $75 \mathrm{~mm}$ sodium phosphate $(\mathrm{pH}$ 7.5) containing $5 \mathrm{~mm}$ dithiothreitol. The enzyme was stored in this buffer at $-20{ }^{\circ} \mathrm{C}$ and no loss of activity was observed over 1 month. The presence of dithiothreitol in the buffer was required to prevent precipitation of the protein during dialysis.

SDS/PAGE analysis of the purified CAD by Coomassie Blue staining revealed a single band at 42.5 $\mathrm{kDa}$ (Fig. 2A) and the molecular mass from size exclusion chromatography was estimated to be $50 \mathrm{kDa}$ (Fig. 2B). An absence of dithiothreitol from the buffer during gel filtration chromatography resulted in
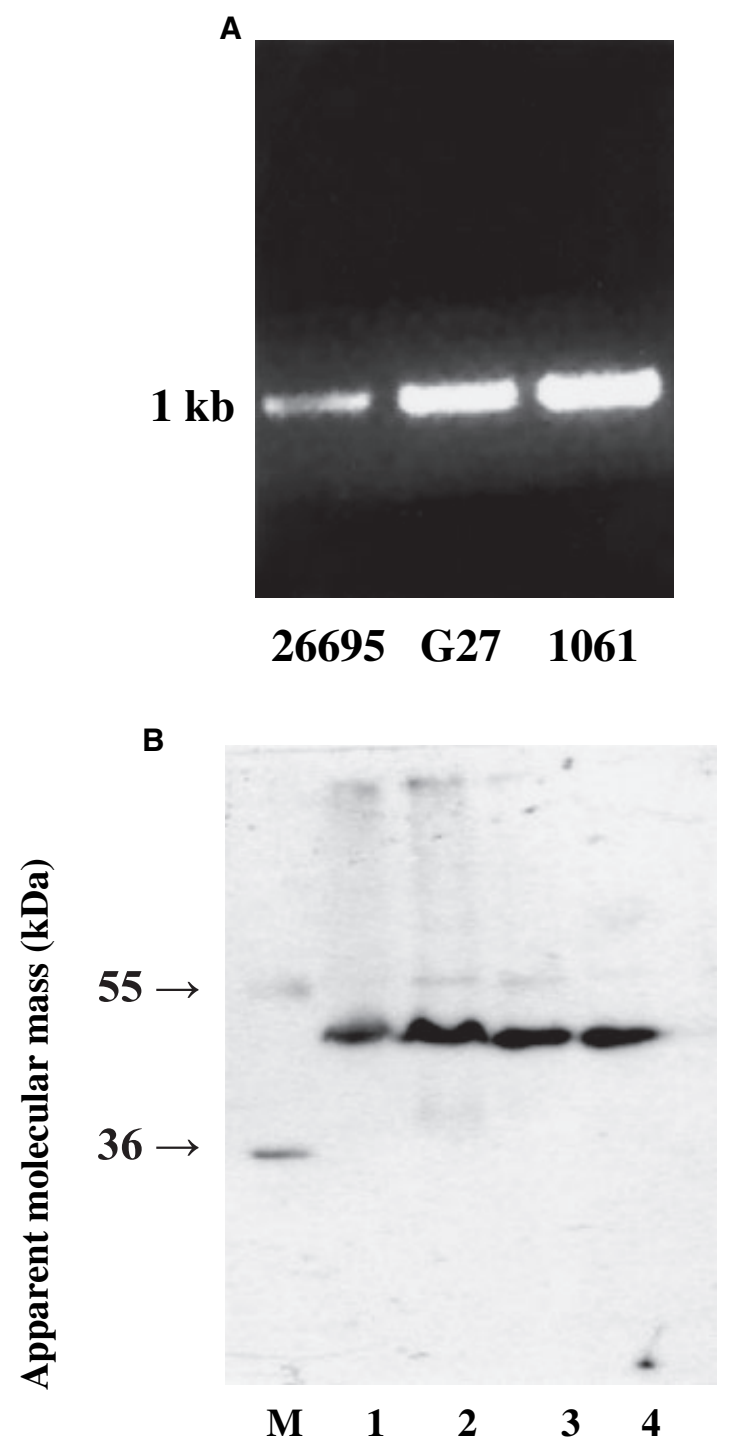

Fig. 1. $P C R$ amplification of $H p C A D$ in different $H$. pylori strains. (A) The PCR amplification of the cinnamyl alcohol dehydrogenase gene from strains 1061, 26695 and G27. The primers used were designed using strain 26695 as the template (http://www.Tigr.org). (B) An affinity purified polyclonal antibody raised in rabbits against HpCAD (1:200), was used to probe the cytosolic fractions of H. pylori strains 26695, 1061, G27 and N6. Protein $(50 \mu \mathrm{g})$ is present in each lane. The blot was developed by enhanced chemiluminescence: lane 1, strain 26695; lane 2, strain 1061; lane 3, strain G27 and lane 4, strain N6.

HpCAD forming higher molecular mass aggregates, presumably due to oxidation of the multiple cysteine residues present in HpCAD.

\section{Subcellular localization}

A previous study of CAD from $M$. bovis BCG showed that $10-20 \%$ of the enzyme was associated with the 

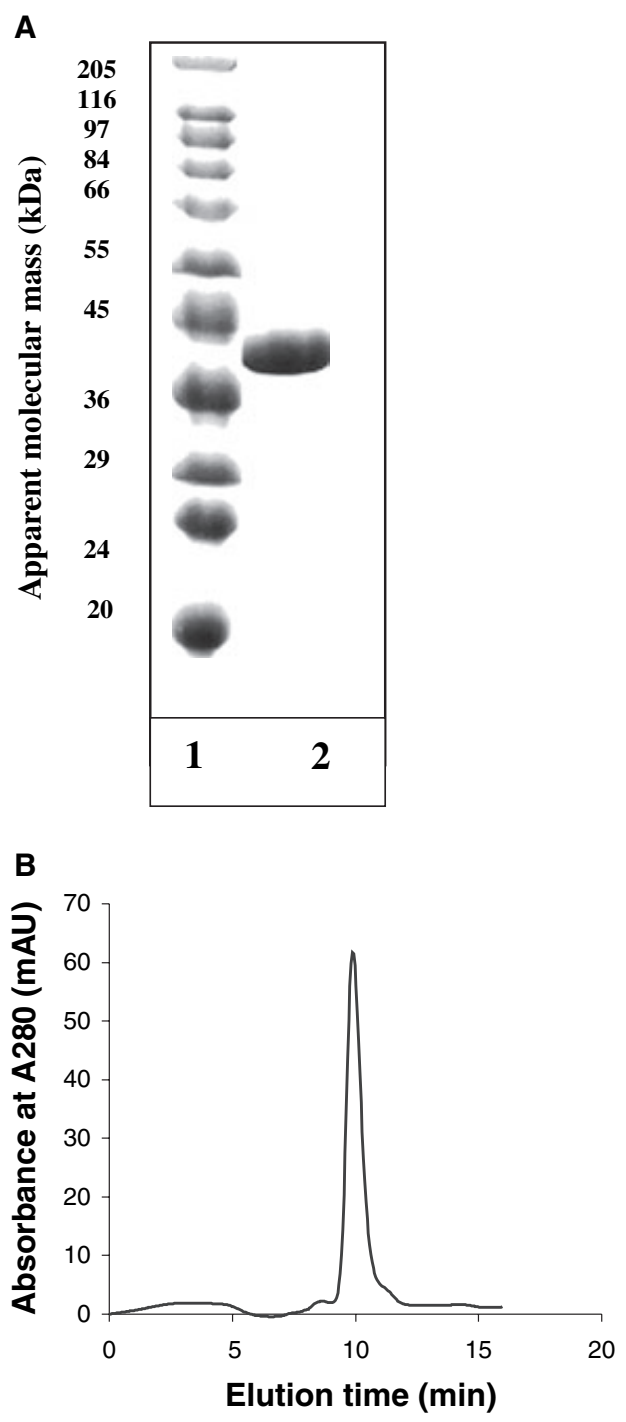

Fig. 2. (A) SDS/PAGE and gel filtration analysis of HpCAD. A sample of HpCAD (lane 2) eluted from the nickel charged iminodiacetic acid column was subjected to SDS/PAGE (15\% acrylamide). The gel was stained with Coomassie Blue revealing a single band at $42.5 \mathrm{kDa}$. The molecular mass markers are shown in lane 1. (B) The profile of HpCAD $(0.2 \mathrm{mg})$ after gel filtration over Superdex 75-HR, a single peak eluting a 9.89 min was observed.

cell envelope of this organism and a role for CAD in lipid metabolism within the envelope was postulated [8]. We examined the subcellular localization of HpCAD in $H$. pylori (Fig. 3), using an affinity-purified antibody against recombinant $\mathrm{HpCAD}$. The majority of the immunoreactive material was found in the cytoplasmic fraction (Fig. 3; lane 2). Detectable amounts of immunoreactivity were also observed in the total envelope fraction (Fig. 3; lane 3). However, this may represent contamination of the envelope fraction with cytosolic components as no immunoreactivity was

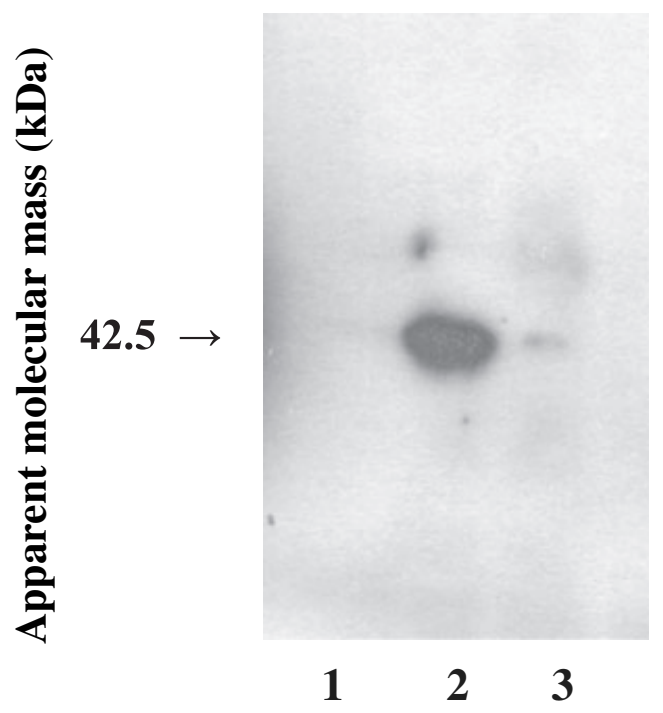

Fig. 3. Subcellular localization of HpCAD. Subcellular fractions of H. pylori were analysed by SDS/PAGE, transferred to poly/vinylidene difluoride) membrane and probed using an affinity purified polyclonal antibody against $\operatorname{HpCAD}(1: 200)$. The blot was developed by ECL with a peroxidase conjugated anti-(rabbit lgG) $\lg (1: 1000)$, lane 1 ; inner membrane fraction, lane 2; cytosolic fraction and lane 3 ; total envelope fraction. Approximately $10 \mu \mathrm{g}$ of protein was loaded in lanes 1-3.

observed in either the inner (Fig. 3; lane 1) or the outer membrane fractions (not shown).

\section{CAD substrate specificity, kinetic parameters and sequence analyses}

The HP1140 gene product of $H$. pylori 26695 is active as a cinnamyl alcohol dehydrogenase. The substrate specificity of the pure enzyme was analysed for several aromatic and aliphatic substrates. The values of the steady-state parameters are summarized in Table 1. The best alcohol substrate was cinnamyl alcohol with a $k_{\text {cat }} / K_{\mathrm{m}}$ value of $126 \mathrm{~s}^{-1} \cdot \mathrm{mm}^{-1}$. Aliphatic alcohols were poorer substrates, with $k_{\text {cat }} / K_{\mathrm{m}}$ values 10 -fold or more lower than the aromatic alcohols. The $k_{\mathrm{cat}} / K_{\mathrm{m}}$ values for aldehydes were higher than those for alcohols. Of the aldehydes, cinnamaldehyde was the best substrate. Acetaldehyde had a 10 -fold lower $k_{\text {cat }} / K_{\mathrm{m}}$ value than cinnamaldehyde. Given these substrate specificities we can confirm the HP1104 gene product is a cinnamyl alcohol dehydrogenase, a putative function that was assigned by TIGR based on homology studies. In general, the substrate specificity was quite similar to that of the S. cerevisiae, M. bovis BCG and plant cinnamyl alcohol dehydrogenases. NADP $(\mathrm{H})$ was the preferred coenzyme and the enzyme showed no activity with $\mathrm{NAD}^{+}$(up to a concentration of $2 \mathrm{mM}$ ). 
Table 1. Kinetic parameters of $H$. pylori cinnamyl alcohol dehydrogenase. Enzymatic activities were measured in $75 \mathrm{~mm}$ sodium phosphate buffer $(\mathrm{pH} 7.5)$ with $2 \mathrm{mM} \mathrm{NADP}^{+}$for oxidation and $0.5 \mathrm{~mm}$ $\mathrm{NADPH}$ for reduction. All parameters were determined at $37^{\circ} \mathrm{C}$.

\begin{tabular}{lccc}
\hline Substrate & $K_{\mathrm{m}}(\mathrm{mm})$ & \multicolumn{1}{c}{$k_{\text {cat }}\left(\mathrm{s}^{-1}\right)$} & $k_{\text {cat }} / K_{\mathrm{m}}\left(\mathrm{s}^{-1} \cdot \mathrm{mM}^{-1}\right)$ \\
\hline Cinnamyl alcohol & $0.10 \pm 0.04$ & $13.3 \pm 1.7$ & $126 \pm 55$ \\
Coniferyl alcohol & $0.11 \pm 0.07$ & $3.5 \pm 1.3$ & $32 \pm 23$ \\
Benzyl alcohol & $0.41 \pm 0.05$ & $8.4 \pm 0.5$ & $21 \pm 3$ \\
Ethanol & $46 \pm 1$ & $7.1 \pm 0.6$ & $0.15 \pm 0.01$ \\
Propanol & $13 \pm 2$ & $12.81 \pm 0.8$ & $0.96 \pm 0.16$ \\
Butanol & $9 \pm 2$ & $5.7 \pm 0.2$ & $0.63 \pm 0.14$ \\
NADP & $0.06 \pm 0.01$ & $7.7 \pm 0.6$ & $128 \pm 24$ \\
Cinnamaldehyde & $0.005 \pm 0.0001$ & $27.4 \pm 1.3$ & $5480 \pm 285$ \\
Coniferylaldehyde & $0.008 \pm 0.0002$ & $2.3 \pm 1$ & $288 \pm 125$ \\
Benzaldehyde & $0.03 \pm 0.002$ & $16.71 \pm 3.3$ & $557 \pm 116$ \\
Acetaldehyde & $0.04 \pm 0.002$ & $25.2 \pm 2.9$ & $630 \pm 79$ \\
NADPH & $0.15 \pm 0.03$ & $15.5 \pm 1.8$ & $103 \pm 6$ \\
Dismutation & $\approx 31$ & $\approx 2.5$ & $\approx 0.08$ \\
\hline
\end{tabular}

${ }^{a}$ Determined with benzyl alcohol at $5 \mathrm{~mm} .{ }^{\mathrm{b}}$ Determined with acetaldehyde at $8 \mathrm{~mm}$.

The highest catalytic activities were observed for the reduction of aldehyde substrates.

An alignment of HpCAD (strain 26695) with CADs from H. pylori strain J99, Campylobacter jejuni, M. bovis BCG, S. cerevisiae and Eucalyptus gunnii demonstrated that the regions of strongest sequence identity occurred in CADs from other bacterial organisms, i.e. H. pylori J99, C. jejuni and M. bovis BCG $(96 \%, 63 \%$ and $42 \%$, respectively). The CADs from the more distantly related S. cerevisiae $(30 \%, 27 \%)$ and E. gunnii $(14 \%)$ had fewer conserved regions, based on this sequence identity analysis.

\section{High substrate inhibition}

HpCAD activity was inhibited by high alcohol and aldehyde substrate concentrations. The degree of high substrate inhibition occurring during alcohol oxidation was related to the structure of the alcohol substrate employed. The aliphatic alcohol substrates, propanol and butanol, produced an inhibition which was less pronounced than that observed for the aromatic alcohol substrates, cinnamyl alcohol, coniferyl alcohol and benzyl alcohol. The initial rates of $\mathrm{NADP}^{+}$reduction were determined at a series of $\mathrm{NADP}^{+}$concentrations in the presence of fixed propanol concentrations at which high-substrate inhibition was apparent $(100 \mathrm{~mm}$ and above). The results, presented as double-reciprocal plots for illustrative purposes (Fig. 4), indicate that the family of lines do not intersect at a common point. This would be consistent with a competitive mechanism in which high concentrations of the alcohol substrate exclude the binding of $\mathrm{NADP}^{+}$, as depicted in the mechanism outlined below:

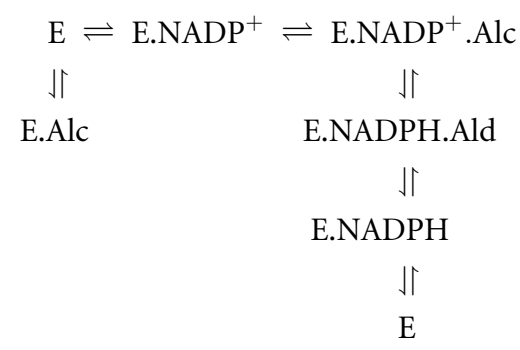

(where Alc and Ald represent the alcohol substrate and aldehyde product, respectively). This mechanism will give an initial-rate equation (Eqn 1) of the form [28,29]:

$$
v=\frac{V_{\max }}{1+\frac{K_{\mathrm{m}}^{\mathrm{NAD}}}{\left[\mathrm{NAD}^{+}\right]}\left(1+\frac{[\mathrm{Alc}]}{K_{\mathrm{i}}}\right)+\frac{K_{\mathrm{m}}^{\mathrm{Alc}}}{[\mathrm{Alc}]}+\frac{K_{\mathrm{s}}^{\mathrm{NAD}} K_{\mathrm{m}}^{\mathrm{Alc}}}{\left[\mathrm{NAD}^{+}\right][\mathrm{Alc}]}\left(1+\frac{[\mathrm{Alc}]}{K_{\mathrm{i}}}\right)}
$$

This indicates that the slopes of the lines (apparent $K_{\mathrm{m}} / V_{\max }$ values) shown in Fig. 4 will not be a linear function of the propanol concentration. Similar behaviour would be expected for this type of substrate inhibition were the enzyme to follow other kinetic mechanisms, such as the Theorell-Chance mechanism or random-order mechanism under conditions

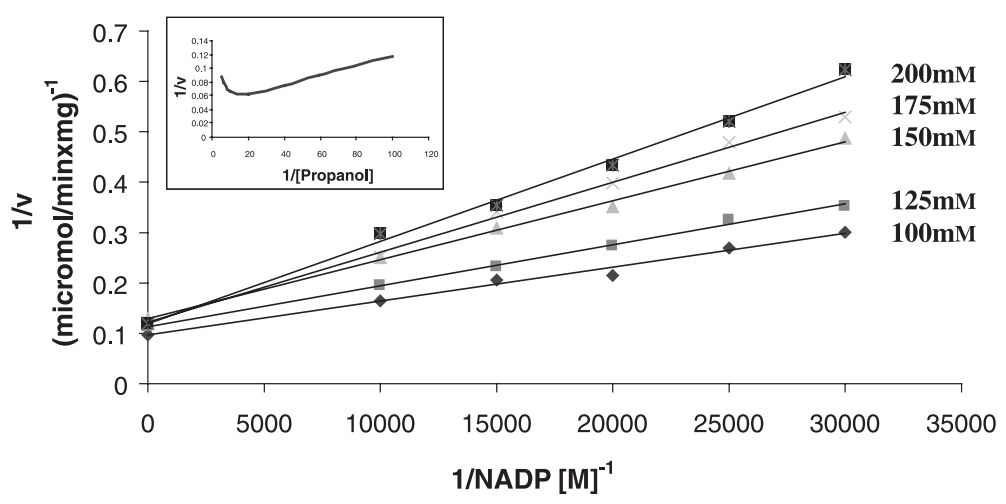

Fig. 4. High substrate inhibition of $\mathrm{HpCAD}$ by propanol. A double-reciprocal plot for varying concentrations of propanol at a fixed concentration of $\mathrm{NADP}^{+}$coenzyme shows substrate inhibition occurring at concentrations above $50 \mathrm{~mm}$ propanol (inset). The type of inhibition by propanol was examined using inhibitory concentrations of propanol and varying $\mathrm{NADP}^{+}$concentrations. From the data presented, the inhibition appears to be competitive. 


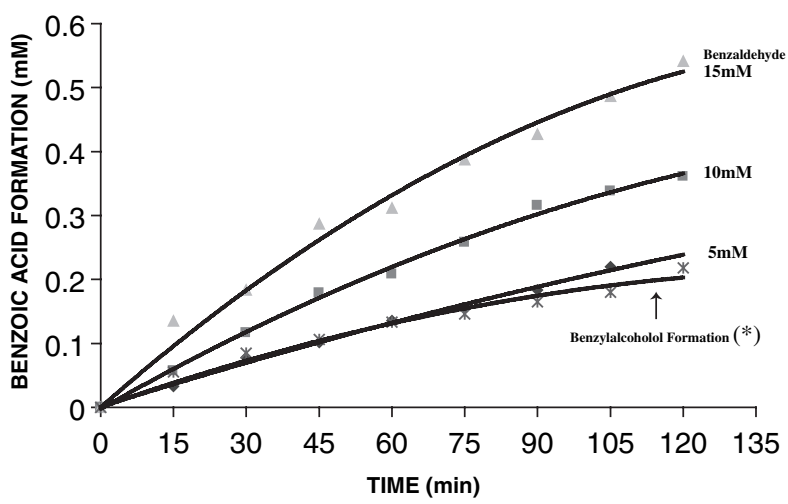

Fig. 5. Dismutation of benzaldehyde by HpCAD. The data shows the formation of benzoic acid as a function of time, at different starting concentrations of benzaldehyde $(15,10$ and $5 \mathrm{~mm})$. After addition of the enzyme, aliquots were removed at $15,30,45,60$, $75,90,105$ and $120 \mathrm{~min}$, and the amount of benzoic acid formed was estimated. The formation of benzyl alcohol is also shown at $5 \mathrm{~mm}$ benzaldehyde $\left({ }^{*}\right)$. Results are expressed as the means of duplicate measurements.

approximating to equilibrium. The complexity of this behaviour precludes the determination of a meaningful value for the inhibitor constant $\left(K_{\mathrm{i}}\right)$.

\section{Dismutation}

A number of alcohol dehydrogenases have been reported to catalyse the dismutation of an aldehyde to equimolar concentrations of the corresponding alcohol and carboxylic acid [30-34]. The HpCAD was found to oxidize benzaldehyde to benzoic acid utilizing $\mathrm{NADP}^{+}$ as a coenzyme (Fig. 5). Through dismutation, the benzyl alcohol and benzoic acid products were produced in equimolar concentrations. The $K_{\mathrm{m}}$ for the dismutation of benzaldehyde was approximately $31 \mathrm{~mm}$ and the $k_{\text {cat }}$ was approximately $2.5 \mathrm{~s}^{-1}$.

\section{Discussion}

Alcohol metabolism by the gastric pathogen $H$. pylori has received little attention with the exception of a few reports that hypothesize that aldehyde production may have a role in pathogenesis [19-27]. Therefore, the aim of this study was to investigate a putative CAD from H. pylori and to characterize the enzyme in terms of its substrate specificity, its ability to dismutate aldehydes and to determine its subcellular localization to gain a better understanding of its role in the metabolism of alcohols and aldehydes.

The HpCAD gene product was overproduced in E. coli, transformed with the pET-HP1104 construct. The enzyme was purified to homogeneity using metal chelate chromatography and had a specific activity of $24 \mu \mathrm{mol} \cdot \mathrm{min}^{-1} \cdot \mathrm{mg}^{-1}$ towards ethanol. SDS/PAGE analysis of the purified HpCAD showed a single band of $42.5 \mathrm{kDa}$ and the molecular mass from size exclusion chromatography was estimated to be $50 \mathrm{kDa}$. From these data, we conclude that the enzyme is a monomer. Most previously characterized CADs were found to be dimeric, although monomeric forms have been isolated from Eucalyptus gunnii and Phaseolus vulgaris [2,35]. In the absence of dithiothreitol the enzyme had a tendency to form higher molecular mass aggregates as determined by gel filtration chromatography.

Subcellular localization studies demonstrated that the CAD was present in the cytosolic fraction of all H. pylori strains tested. A small amount of immunoreactivity was detectable in the total envelope fraction. This latter observation must be interpreted with caution, as it is possible that the total envelope fraction contains a small amount of cytosolic material. In contrast, a significant proportion of the CAD expressed by $M$. bovis BCG is found in the cell envelope (10$20 \%)[8]$.

Substrate specificity analysis demonstrated that the HpCAD had a preference for aromatic aldehydes and alcohols. Furthermore, HpCAD was found to reduce aldehyde substrates that are used by plant CADs for the biosynthesis of lignin (e.g. cinnamaldehyde and coniferylaldehyde). Aliphatic and aromatic aldehydes were also reduced by the enzyme and cinnamaldehyde had the highest $k_{\text {cat }} / K_{\mathrm{m}}$ value. Having confirmed the functional activity of HP1104 as a CAD enzyme we propose that the gene encoding HP1104 be designated $c a d$. This designation is further supported by the presence of several sequence motifs present in the HpCAD sequence which are common in zinc-binding medium chain dehydrogenases [9]: the putative 'catalytic zinc' ligands present at Cys42, His64 and Cys160; the pattern ' $\mathrm{GX}_{1-3} \mathrm{GX}_{1-3} \mathrm{G}$ ' which appears in the nucleotide binding region as Gly184, Gly186 and Gly189; and the four 'structural zinc' ligands at Cys95, Cys98, Cys101 and Cys109. Finally, a Ser48 is present which may play a role in the removal of the proton from alcohol molecules during the catalytic process is also present [9].

Comparison of the substrate specificity between CADs from different organisms is difficult due to variations in the alcohol and aldehyde substrates employed by different research groups. Furthermore, high substrate inhibition, where it occurs, can make specificity studies complicated, as use of a single substrate concentration may not accurately reflect relative activities if that concentration were at an inhibitory level. However, a comparison of $k_{\text {cat }} / K_{\mathrm{m}}$ values recorded for M. bovis BCG, S. cerevisiae and Arabidopsis thaliana 
CADs with cinnamyl alcohol and aldehyde as substrates show that HpCAD is more efficient at utilizing these substrates $[8-10,36]$. The HpCAD enzyme also had a marked preference for the coenzyme $\operatorname{NADP}(\mathrm{H})$, with little or no activity towards $\operatorname{NAD}(\mathrm{H})$. Similar coenzyme preference was attributed to the Ser212 residue that Lauvergeat et al. found was responsible for determining the coenzyme specificity of E. gunnii CAD [37]. Larroy et al. also reported a Ser residue at position 211 in S. cerevisiae, as opposed to an Asp residue commonly found in ADH enzymes with a preference for $\mathrm{NAD}(\mathrm{H})$ as a coenzyme [9]. Sequence analysis showed there was a conserved Ser218 residue in H. pylori (strains 26695 and J99) which is also present in C. jejuni. In general, sequence alignments showed the strongest identity between CADs from H. pylori 26695 and H. pylori $\mathrm{J} 99$ (96\%), C. jejuni (63\%) and M. bovis BCG $(42 \%)$.

Marked high substrate inhibition was observed in both the oxidative and reductive directions for HpCAD. The enzyme was more sensitive to high substrate inhibition when the reaction was assayed in the direction of aldehyde reduction, with such inhibition becoming apparent at $250 \mu \mathrm{M}$ cinnam aldehyde. Similar high substrate inhibition was previously identified for a CAD from Eucalyptus by Lauvergeat et al. [37].

Significantly, HpCAD is capable of dismutating benzaldehyde to form benzyl alcohol and benzoic acid. The oxidation of benzaldehyde produces NADPH, which subsequently reduces another molecule of benzaldehyde leading to dismutation (Scheme 1). Thus the formation of both alcohol and carboxylic acid products is achieved with no net change in coenzyme

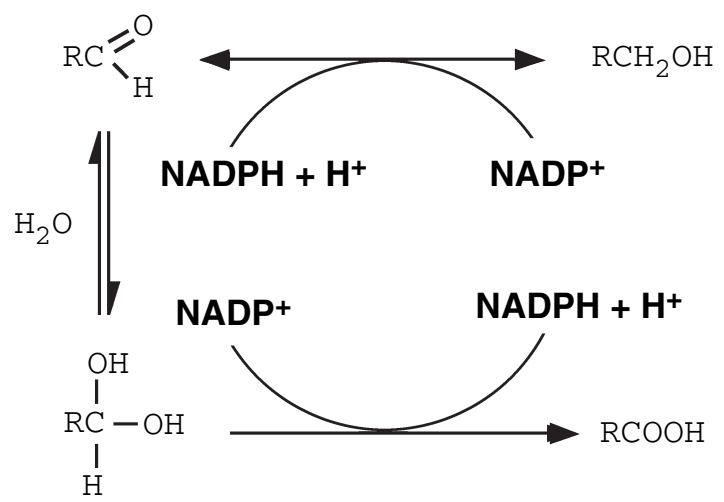

Overall reaction 2 Aldehyde $+\mathrm{H}_{2} \mathrm{O}=$ acid + alcohol

Scheme 1. Dismutation schematic. In the dismutation reaction of $\mathrm{HpCAD}, \mathrm{RCHO}$ is an aldehyde, $\mathrm{RCH}(\mathrm{OH})_{2}$ is a hydrated aldehyde, $\mathrm{RCOOH}$ is the corresponding carboxylic acid and $\mathrm{RCH}_{2} \mathrm{OH}$ is the corresponding alcohol. oxidation and so the redox potential of the environment within the cell remains unaltered. Thus, dismutation provides an important means of reducing the concentration of potentially reactive aldehydes within the bacterium. The $k_{\text {cat }} / K_{\mathrm{m}}$ for benzaldehyde dismutation is $0.08 \mathrm{~s}^{-1} \cdot \mathrm{mm}^{-1}$. This is comparable to the $k_{\text {cat }} / K_{\mathrm{m}}$ for the formation of acetaldehyde from the oxidation of ethanol which is $0.15 \mathrm{~s}^{-1} \cdot \mathrm{mm}^{-1}$. However, the $k_{\mathrm{cat}} / K_{\mathrm{m}}$ values for dismutation cannot be directly compared with $k_{\mathrm{cat}} / K_{\mathrm{m}}$ values for the oxidation of alcohols or reduction of aldehydes. These latter reactions involve the binding of a substrate at a single active site and display simple saturation kinetics. The dismutation reaction, by contrast, involves substrate binding twice during the catalytic cycle [29-33]. Thus $V_{\max }$ does not represent saturation of a single substrate-binding site.

In conclusion, this work confirms the assignation of HP1104 as a CAD based on our kinetic characterization of its substrate specificity and the presence of several motifs specific to this class of enzymes. Additionally, the presence of dismutase activity is significant as, to the best of our knowledge, this is the first report of such an activity for this class of enzyme. This activity may provide the pathogen with a potential means of reducing the amount of aldehydes within the bacterium. Consequently, the hypothesis implicating H. pylori derived aldehydes in pathogenesis [e.g. 26]. needs to be reassessed in view of these findings.

\section{Experimental procedures}

\section{Materials}

Restriction enzymes were from New England Biolabs (Herts, England). Taq-High Fidelity was from Roche (Basel, Switzerland). T4 DNA Ligase was from Invitrogen (Breda, the Netherlands). Bacterial media, iminodiacetic acid-Sepharose 6B fast flow, NADP, NADPH, alcohol and aldehyde substrates and IPTG were obtained from Sigma Aldrich (Sigma, Poole, Dorset, UK).

\section{Bacterial strains and plasmids}

H. pylori strains 26695 (ATCC 700392) [38], 1061 [39], N6 (clinical isolate) and G27 were a kind gift from A. Van Vliet and J. Kusters (G27 was originally from A. Covacci - all Erasmus MC, University Medical Centre, the Netherlands). Escherichia coli DH5 $\alpha$ was used for cloning procedures. Genomic DNA from H. pylori (strains 1061, 26695 and G27) was used to amplify the HP1104 gene by PCR. The pET 16b vector (Novagen, Darmstadt, Germany) was used to clone and overexpress the HP1104 gene in E. coli BL21(DE3)plysS with a His tag on the $\mathrm{N}$ terminus. E. coli was grown at $37{ }^{\circ} \mathrm{C}$ 
in LB medium supplemented with ampicillin $\left(100 \mu \mathrm{g} \cdot \mathrm{mL}^{-1}\right)$ and chloramphenicol $\left(34 \mu \mathrm{g} \cdot \mathrm{mL}^{-1}\right)$ to select for the desired constructs.

\section{Cloning methods}

All DNA manipulations were performed under standard conditions as described by Sambrook et al. [40]. The cad gene was amplified by PCR using genomic DNA from $H$. pylori 26695 as the template and the oligonucleotides 5'-CGCCATATGAGACAATCTAAA- ${ }^{\prime}$ ' and 5'-CGCGGA TCCATCAAACGATTTTTTCATA- ${ }^{\prime}$, as the forward and reverse primers, respectively. These primers were designed to introduce an $N d e 1$ site at the $5^{\prime}$-end and a $B a m \mathrm{H} 1$ site at the $3^{\prime}$-end (underlined). The PCR conditions used were those recommended by the manufacturer (Roche, Basel, Switzerland) for Taq High Fidelity polymerase.

The amplified PCR product containing the HP1104 gene was cloned into the $\mathrm{pET} 16 \mathrm{~b}$ vector (Novagen; all pET vectors are derived from the plasmid pBR322). The resulting construct was named pET-HP1104. The construct was sequenced in both directions (DNA sequencing facility, University of Cambridge, UK) to verify that no mutations were introduced by the PCR reaction.

\section{Purification of the HP1104 gene product}

Over production of the recombinant HpCAD was achieved in E. coli BL21(DE3)plysS. Cells harbouring pET-HP1104 were grown to $D_{600}=0.6$, in LB media containing ampicillin $\left(100 \mu \mathrm{g} \cdot \mathrm{mL}^{-1}\right)$ and chloramphenicol $\left(34 \mu \mathrm{g} \cdot \mathrm{mL}^{-1}\right)$. Production of HpCAD was induced by addition of $1 \mathrm{~mm}$ isopropyl thio- $\beta$-D-galactoside, followed by incubation at room temperature, to minimize inclusion body formation. After $14 \mathrm{~h}$, the cells were harvested by centrifugation at $5000 \mathrm{~g}$, for $30 \mathrm{~min}$ at $4{ }^{\circ} \mathrm{C}$. For protein purification, the cells from a $600 \mathrm{~mL}$ culture were resuspended in $30 \mathrm{~mL}$ of binding buffer $(5 \mathrm{mM}$ imidazole, $0.5 \mathrm{M} \mathrm{NaCl}, 20 \mathrm{mM}$ Tris/ $\mathrm{HCl}, \mathrm{pH} 7.9$ ) and sonicated on ice for $3 \times 5 \mathrm{~min}$ (Soniprep 150, Sanyo). The resulting cell lysate was centrifuged at $5000 \mathrm{~g}$ for $1 \mathrm{~h}$ at $4{ }^{\circ} \mathrm{C}$, and the supernatant filtered $(0.45 \mu \mathrm{m})$ prior to loading onto a nickel-charged iminodiacetic acid column. The unbound material was eluted using 10 column volumes of binding buffer and six column volumes of wash buffer $(60 \mathrm{~mm}$ imidazole, $0.5 \mathrm{M} \mathrm{NaCl}, 20 \mathrm{~mm}$ Tris/ $\mathrm{HCl}, \mathrm{pH}$ 7.9). The recombinant CAD protein was then eluted over seven column volumes with elution buffer (500 mm imidazole, $0.5 \mathrm{~m} \mathrm{NaCl}, 20 \mathrm{~mm}$ Tris/HCl, $\mathrm{pH}$ 7.9).

SDS/PAGE was performed essentially as described by Laemmli [41] to monitor the purity of each fraction. Proteins were visualized by Coomassie blue staining. The purified protein was dialysed against $75 \mathrm{mM}$ sodium phosphate buffer (pH 7.5) containing $5 \mathrm{~mm}$ dithiothreitol (dithiothreitol). Protein concentrations were determined by the Bradford method [42]. A polyclonal antibody was produced in a New Zealand White rabbit with an emulsion of purified recombinant HpCAD in Freund's complete adjuvant, using subcutaneous immunization and following standard procedures at the Bio Resource Unit, Trinity College. The polyclonal anti-HpCAD Igs were affinity purified as required from preparative Western blots of the purified recombinant protein as described by Harlow and Lane [43].

\section{Native molecular mass determination}

The relative molecular mass of the purified enzyme was determined using a Superdex 75-HR gel filtration column equilibrated with $75 \mathrm{~mm}$ sodium phosphate buffer $(\mathrm{pH} 7.5)$ containing $5 \mathrm{~mm}$ dithiothreitol, using an AKTA FPLC system (Amersham Pharmacia, Uppsala, Sweden). A standard curve was constructed using albumin, ovalbumin, chymotrypsinogen A and ribonuclease A (Amersham Pharmacia). CAD samples $(0.2 \mathrm{mg})$ were applied at a flow rate of $1 \mathrm{~mL} \cdot \mathrm{min}^{-1}$.

\section{Enzyme assays}

The kinetic parameters were determined spectrophotometrically at $37{ }^{\circ} \mathrm{C}$ using an Agilent 8453 diode array spectrophotometer (Agilent Technologies, Palo Alto, CA, USA). The purified enzyme was assayed both for the reduction of aldehydes (forward reaction) and the oxidation of alcohols (reverse reaction). The activities towards different aldehydes were assayed in reaction mixtures $(2 \mathrm{~mL})$ containing $75 \mathrm{~mm}$ sodium phosphate buffer ( $\mathrm{pH} 7.5$ ) with $0.5 \mathrm{~mm}$ NADPH. The decrease in NADPH absorbance at $340 \mathrm{~nm}$ was followed to assess the enzymatic activity towards the aldehydes. The reduction of cinnamaldehyde and coniferylaldehyde was followed at 366 and $400 \mathrm{~nm}$, respectively. The molar extinction coefficients $(\varepsilon)$ used ( $\mathrm{pH} 7.5)$ were: $\varepsilon_{340}=6.22 \mathrm{~mm}^{-1} \cdot \mathrm{cm}^{-1}$ and $\varepsilon_{366}=3.3 \mathrm{mM}^{-1} \cdot \mathrm{cm}^{-1}$ for NADPH [44], although more accurate extinction coefficients have been determined under defined conditions [45]. The extinction coefficient used for coniferylaldehyde was $\varepsilon_{400}=4.7 \mathrm{~mm}^{-1} \cdot \mathrm{cm}^{-1}[8-10]$. The activities with alcohols were measured in a final volume of $2 \mathrm{~mL}$ in $75 \mathrm{~mm}$ sodium phosphate buffer ( $\mathrm{pH} 7.5$ ) containing $2 \mathrm{mM} \mathrm{NADP}{ }^{+}$. The formation of NADPH at $340 \mathrm{~nm}$ was followed for most alcohol substrates. The oxidation of cinnamyl alcohol was determined at $366 \mathrm{~nm}$ and coniferyl alcohol at $400 \mathrm{~nm}$ [8-10]. The steady-state parameters were determined by fitting the initial rates to the Michaelis-Menten equation using the ENZFITTER program.

\section{High substrate inhibition studies}

The initial rate of $\mathrm{NADP}^{+}$reduction was determined at $37^{\circ} \mathrm{C}$ in $75 \mathrm{~mm}$ sodium phosphate buffer (pH 7.5) with 
varying concentrations of $\mathrm{NADP}^{+}$and fixed concentrations of propanol at which high substrate inhibition occurred. The initial rates of $\mathrm{NADP}^{+}$reduction were determined at 100, 125, 150, 175 and $200 \mathrm{~mm}$ propanol.

\section{Dismutation-benzaldehyde oxidation}

Assays for aldehyde dismutation were carried out using aliquots of the reaction mixture solution removed and analysed on a Nova-Pak C18 $(3.9 \times 150 \mathrm{~mm})$ HPLC column using the method described by Shearer et al. [46]. The assays $(1 \mathrm{~mL})$ were carried out in $75 \mathrm{~mm}$ sodium phosphate buffer ( $\mathrm{pH} 7.5$ ) containing $2 \mathrm{mM} \mathrm{NADP}^{+}$at $37{ }^{\circ} \mathrm{C}$ in the presence of various amounts of benzaldehyde. The reaction was quenched by addition of the mixture to the mobile phase (acetonitrile/acetic acid/ water, $30: 1: 69, \mathrm{v} / \mathrm{v} / \mathrm{v}$ ) of the HPLC system. The composition of the reaction mixtures was determined using a Millipore Waters (Mississauga, Canada) liquid chromatography UV detector set at $254 \mathrm{~nm}$ [46]. Assays were performed in duplicate.

\section{Subcellular localization}

The subcellular fractions of $H$. pylori were obtained as described previously [47]. Briefly, H. pylori was grown for $48 \mathrm{~h}$ on Columbia agar plates containing $7 \%(\mathrm{v} / \mathrm{v})$ horse blood. The bacteria were harvested and resuspended in $20 \mathrm{~mm}$ Tris ( $\mathrm{pH}$ 7.5). The cells were lysed by sonication and the total membrane fraction collected by centrifugation $\left(40000 \mathrm{~g}, 30 \mathrm{~min}, 4^{\circ} \mathrm{C}\right.$ ). Membranes were resuspended in $20 \mathrm{~mm}$ Tris ( $\mathrm{pH} 7.5)$ containing $2 \%(\mathrm{w} / \mathrm{v})$ sodium lauryl sarcosine and incubated at room temperature for $30 \mathrm{~min}$. Outer membranes were collected by centrifugation (40 $000 \mathrm{~g}$, $30 \mathrm{~min}, 4^{\circ} \mathrm{C}$ ) and washed three times with Milli Q water (Millipore, Mississauga, Canada). The remaining supernatant was used as the inner membrane enriched fraction. SDS/PAGE and Western blotting were used to identify the subcellular localization of HpCAD. Blots were probed with affinity-purified rabbit anti-(HpCAD polyclonal IgG) Ig.

\section{Acknowledgement}

BM was funded by a studentship from Health Research Board of Ireland.

\section{References}

1 Blanco-Portales R, Medina-Escobar N, Lopez-Raez JA, Gonzalez-Reyes JA, Villalba JM, Moyano E, Caballero JL \& Munoz-Blanco J (2002) Cloning, expression and immunolocalization pattern of a cinnamyl alcohol dehydrogenase from strawberry. J Exp Botany 53, 1723-1734.
2 Grima-Pettenati J, Campargue C, Boudet A \& Boudet AM (1994) purification and characterization of cinnamyl alcohol dehydrogenase isoforms from Phaseolus vulgaris. Phytochemistry 37, 941-947.

3 Rishi AS, Nelson ND \& Goyal A (2001) Improvement of Populus through genetic engineering. Indian J Plant Physiol 6, 119-126.

4 Ralph J, MacKay JJ, Hatfield RD, O’Malley DM, Whetten RW \& Sederoff RR (1997) Abnormal lignin in a loblolly pine mutant. Science 277, 235-239.

5 Jung HG \& Ni W (1998) Lignification of plant cell walls: Impact of genetic manipulation. Proc Natl Acad Sci USA 95, 12742-12743.

6 Boerjan W, Baucher M, Chabbert B, Petit-Conil M, Leple JC, Pilate G, Cornu D, Monties B, Van Montagu M, Van Doorsselaere J, et al. (1997) Genetic modification of lignin biosynthesis in quaking aspen (Populus Tremuloides) and poplar (Populus tremula $\times$ Populus alba). In Micropropagation. Genetic Engineering, and Molecular Biology of Populus (Klopfenstein NB, ed), pp. 193-205. USDA Forest Service, Rocky Mountain Forest and Range Experiment Station, Fort Collins, CO.

7 Lapierre C, Pollet B, Petit-Concil M, Toval G, Romero J, Pilate G, Leple JC, Boerjan W, Ferret V, Nadai VD \& Jouanin L (1999) Structural alterations of lignin $s$ in transgenic poplars with depressed cinnamyl alcohol dehydrogenase or caffeic acid O-methyltransferase activity have an opposite impact on the efficiency of industrial kraft pulping. Plant Physiol 119, 153-163.

8 Wilkin JM, Soetaert K, Stelandre M, Buyssens P, Castillo G, Demoulin V, Bottu G, Laneelle MA, Daffe M \& De Bruyn J (1999) Overexpression, purification and characterization of Mycobacterium bovis BCG alcohol dehydrogenase. Eur J Biochem 262, 299-307.

9 Larroy C, Pares X \& Biosca JA (2002) Characterization of a Saccharomyces cerevisiae NADP(H)-dependent alcohol dehydrogenase (ADHVII), a member of the cinnamyl alcohol dehydrogenase family. Eur $J$ Biochem 269, 5738-5745.

10 Larroy C, Fernandez MR, Gonzalez E, Pares X \& Biosca JA (2003) Properties and functional significance of Saccharomyces cerevisiae ADH6 product as a broad specificity NADPH-dependent alcohol dehydrogenase: relevance in aldehyde reduction. Chemico-Biol Interacts 143-144, 229-238.

11 Tomb JF, White O, Kerlavage AR, Clayton RA, Sutton GG, Fleischmann RD, Ketchum KA, Klenk HP, Gill S, Dougherty BA, et al. (1997) The complete genome sequence of the gastric pathogen Helicobacter pylori. Nature 388, 539-547.

12 Ang S, Lee CZ, Peck K, Sindici M, Matrubutham U, Gleeson MA \& Wang JT (2001) Acid-induced gene 
expression in Helicobacter pylori: study in genomic scale by microarray. Infect Immun 69, 1679-1686.

13 Haas G, Karaali G, Ebermayer K, Metzger WG, Lamer S, Zimny-Arndt U, Diescher S, Goebel UB, Vogt K, Roznowski AB, et al. (2002) Immunoproteomics of Helicobacter pylori infection and relation to gastric disease. Proteomics 2, 313-324.

14 Konturek JW (2003) Discovery by Jaworski of Helicobacter pylori and its pathogenetic role in peptic ulcer, gastritis and gastric cancer. J Physiol Pharmacol 54, 23-41.

15 Marshall BJ \& Warren JR (1984) Unidentified curved Bacilli in the stomach of patients with gastritis and peptic ulceration. Lancet 1, 1311-1315.

16 Forman D, Webb P \& Parsonnet J (1994) H. pylori and gastric cancer. Lancet 343, 243-244.

17 Bayerdorffer E, Neubauer A, Rudolph B, Thiede C, Lehn N, Eidt S \& Stolte M (1995) Regression of primary gastric lymphoma of mucosa-associated lymphoid tissue type after cure of Helicobacter pylori infection. MALT Lymphoma Study Group. Lancet 345, 15911594.

18 Prinz C, Hafsi N \& Voland P (2003) Helicobacter pylori virulence factors and the host immune response: implications for therapeutic vaccination. Trends Microbiol 11, 134-138.

19 Salmela KS, Roine RP, Hook-Nikanne J, Kosunen TU \& Salaspuro M (1994) Acetaldehyde and ethanol production by Helicobacter pylori. Scand J Gastroenterol 29, 309-312.

20 Salmela KS, Salaspuro M, Gentry RT, Methuen T, Hook-Nikanne J, Kosunen TU \& Roine RP (1994) Helicobacter infection and gastric ethanol metabolism. Alcohol Clin Exp Res 18, 1294-1299.

21 Salmela KS, Sillanaukee P, Itala L, Vakevainen S, Salaspuro M \& Roine RP (1997) Binding of acetaldehyde to rat gastric mucosa during ethanol oxidation. J Laboratory Clin Med 129, 627-633.

22 Homann N, Jousimies-Somer H, Jokelainen K, Heine R \& Salaspuro M (1997) High acetaldehyde levels in saliva after ethanol consumption: methodological aspects and pathogenetic implications. Carcinogenesis 18, 1739-1743.

23 Salaspuro MP (2003) Acetaldehyde, microbes, and cancer of the digestive tract. Crit Rev Clin Laboratory Sci 40, 183-208.

24 Roine RP, Salmela KS \& Salasporo M (1995) Alcohol metabolism in Helicobacter pylori-infected stomach. Ann Med 27, 583-588.

25 Matysiak-Budnik T, Karkkainen P, Meuthuen T, Roine RP \& Salasporo M (1995) Inhibition of gastric cell proliferation by acetaldehyde. J Pathol 177, 317-322.

26 Figura N (1997) Helicobacter pylori factors involved in the development of gastroduodenal mucosal damage and ulceration. J Clin Gastroenterol 25, 149-163.

27 Kaihovaara P, Salmela KS, Roine RP, Kosunen TU \& Salaspuro M (1994) Purification and characterization of
Helicobacter pylori alcohol dehydrogenase. Alcohol Clin Exp Res 18, 1220-1225.

28 McDonald AG \& Tipton KF (2003) Kinetics of catalyzed reactions - biological. In Encyclopedia of Catalysis (Horváth IT, ed), pp. 395-471. John Wiley \& Sons, Inc, Hoboken, NJ.

29 Dixon M, Webb EC, Thorne CJR \& Tipton KF (1979) Enzyme Inhibitors. In Enzymes (Dixon M \& Webb EC eds) pp. 126-137. Longman, London.

30 Daussmann T, Aivasidis A \& Wandrey C (1997) Kinetic data and new enzymatic activities of Methanosarcina barkeri grown on methanol as sole carbon source.

Water Sci Technol 36, 175-182.

31 Steinbuchel A \& Schlegel HG (1984) A multifunctional fermentative alcohol dehydrogenase from the strict aerobe Alcaligenes eutrophus: purification and properties. Eur J Biochem 141, 555-564.

32 Winberg JO \& McKinley-McKee JS (1998) Drosophila melanogaster alcohol dehydrogenase: mechanism of aldehyde oxidation and dismutation. Biochem J 329, 561-570.

33 Henehan GT, Chang SH \& Oppenheimer NJ (1995) Aldehyde dehydrogenase activity of Drosphila melanogaster alcohol dehydrogenase: burst kinetics at high $\mathrm{pH}$ and aldehyde dismutase activity at physiological $\mathrm{pH}$. Biochemistry 34, 12294-12301.

34 Oppenheimer NJ \& Henehan GT (1995) Horse liver alcohol dehydrogenase-catalyzed aldehyde oxidation. The sequential oxidation of alcohols to carboxylic acids under NADH recycling conditions. Adv Exp Medical Biol 372, 407-415.

35 Hawkins SW \& Boudet AM (1994) Purification and characterisation of cinnamyl alcohol dehydrogenase isoforms from the periderm of Eucalyptus gunni Hook. Plant Physiol 104, 75-84.

36 Somssich IE, Wernert P, Kiedrowski S \& Hahlbrock K (1996) Arabidopsis thaliana defense-related protein ELI3 is an aromatic alcohol: $\mathrm{NADP}(+)$ oxidoreductase. Proc Natl Acad Sci USA 93, 14199-14203.

37 Lauvergeat V, Kennedy K, Feuillet C, McKie JH, Gorrichon L, Baltas M, Boudet AM, Grima-Pettenati J \& Douglas KT (1995) Site-directed mutagenesis of a serine residue in cinnamyl alcohol dehydrogenase, a plant NADPH-dependent dehydrogenase, affects the specificity for the coenzyme. Biochemistry 34, 1242612434.

38 Marais A, Mendz GL, Hazell SL \& Megraud F (1999) Metabolism and genetics of Helicobacter pylori: the genome era. Microbiol Mol Biol Rev 63, 642-674.

39 Goodwin A, Kersulyte D, Sisson G, Veldhuyzen VZ, Berg DE \& Hoffman PS (1998) Metronidazole resistance in Helicobacter pylori is due to null mutations in a gene $(r d x A)$ that encodes an oxygen-insensitive NADPH nitroreductase. Mol Microbiol 28, 383-393. 
40 Sambrook J, Fritsch EF \& Maniatis T (1989) Molecular Cloning. A Laboratory Manual, 2nd edn. Cold Spring Harbor Laboratory Press, Cold Spring Harbor, NY.

41 Laemmli UK (1970) Cleavage of structural proteins during the assembly of the head of bacteriophage T4. Nature 227, 680-685.

42 Bradford MM (1976) A rapid and sensitive method for the quantitation of microgram quantities of protein utilizing the principle of protein-dye binding. Anal Biochem 72, 248-254.

43 Harlow E \& Lane D (1988) Antibodies; A Laboratory Manual. Cold Spring Harbor Laboratory Press, Cold Spring Harbor, NY.
44 Horecker BL \& Kornberg A (1948) The extinction coefficients of the reduced band of pyridine nucleotides. J Boil Chem 175, 385-390.

45 Ziegenhorn J, Senn M \& Bücher T (1976) Molar absorptivities of beta-NADH and beta-NADPH. Clin Chem 22, 151-160.

46 Shearer GL, Kim K, Lee KM, Wang CK \& Plapp BV (1993) Alternative pathways and reactions of benzyl alcohol and benzaldehyde with horse liver alcohol dehydrogenase. Biochemistry 32, 11186-11194.

47 Doig P \& Trust TJ (1994) Identification of surfaceexposed outer membrane antigens of Helicobacter pylori. Infect Immun 62, 4526-4533. 